\title{
Articles
}

\section{Cardiovascular risk factors clustering with endogenous hyperinsulinaemia predict death from coronary heart disease in patients with Type II diabetes}

\author{
S. Lehto ${ }^{1}$, T. Rönnemaa ${ }^{2}$, K. Pyöräläa ${ }^{1}$ M. Laakso ${ }^{1}$ \\ ${ }^{1}$ Department of Medicine, Kuopio University Hospital, Kuopio, Finland \\ ${ }^{2}$ Department of Medicine, Turku University Central Hospital, Turku, Finland
}

\begin{abstract}
Aims/hypothesis. Information on the association of hyperinsulinaemia with coronary heart disease (CHD) in patients with Type II (non-insulin-dependent) diabetes is limited and controversial. Therefore, we carried out a prospective study to examine the predictive value of fasting plasma insulin and "hyperinsulinaemia cluster" with regard to the risk of CHD mortality.

Methods. At baseline risk factors for CHD were determined in 902 patients aged 45 to 64 years with Type II diabetes not treated by insulin ( 499 men and 403 women). These patients were followed up to 7 years for CHD mortality.

Results. Coronary heart disease mortality $(16.2 \%$ in men, $9.2 \%$ in women) increased significantly in men with increasing plasma insulin tertiles $(p=0.006)$ and in both sexes combined $(p=0.010)$ but not in women $(p=0.090)$. The predictive value of hyperinsulinaemia with regard to death from CHD was inde-
\end{abstract}

pendent of conventional cardiovascular risk factors but not of risk factors clustering with hyperinsulinaemia. By applying factor analysis and principal component analysis we showed that "hyperinsulinaemia cluster" (a factor having high positive loadings for body mass index, triglycerides and insulin; and a high negative loading for high-density lipoprotein cholesterol) was predictive of death from CHD in patients with Type II diabetes (hazard ratio with $95 \%$ confidence intervals $1.43(1.18,1.73), p<0.001)$.

Conclusion/interpretation. Our results support the notion that cardiovascular risk factors clustering with endogenous hyperinsulinaemia increase the risk of death from CHD in patients with Type II diabetes not treated with insulin. [Diabetologia (2000) 43: 148-155]

Keywords Type II diabetes, death from CHD, insulin, insulin resistance syndrome, lipids, hypertension, smoking, central obesity, urinary protein, sex.
The occurrence of coronary heart disease (CHD) and other manifestations of atherosclerotic vascular disease are substantially increased in patients with Type II (non-insulin-dependent) diabetes. Mortality from CHD and the incidence of non-fatal CHD events are two to four times higher in patients with Type II dia-

Received: 6 August 1999 and in final revised form: 22 October 1999

Corresponding author: M. Laakso, MD, Department of Medicine, University of Kuopio, SF-70210 Kuopio, Finland Abbreviations: CHD, Coronary heart disease; WHO, World Health Organization; HDL, high-density lipoprotein cholesterol; HR, hazard ratio. betes than in age-matched non-diabetic subjects [1-4]. The reasons for accelerated atherosclerosis in diabetic subjects are still not completely understood.

Type II diabetes is known to be associated with an adverse pattern of cardiovascular risk factors, including hypertension, central obesity, increased levels of plasminogen activator inhibitor 1 and fibrinogen, and with dyslipidaemia which is characterised mainly by increased serum total triglycerides and low highdensity lipoprotein (HDL) cholesterol [5-9]. These risk factors also cluster with hyperinsulinaemia and insulin resistance. Although much of the excess risk to develop CHD in diabetic patients can be accounted for by adverse changes in cardiovascular risk fac- 
tors, a considerable proportion of it remains unexplained. Therefore, unknown risk factors or risk factors specific for Type II diabetes, hyperglycaemia and insulin resistance must be crucial for the development of accelerated atherosclerosis in these patients. Indeed, recent studies have indicated that hyperglycaemia is an important and independent risk factor for cardiovascular disease in patients with Type II diabetes [10-12].

Although several prospective epidemiological studies have shown that hyperinsulinaemia predicts the risk of CHD in non-diabetic subjects, [13-15] there is still a controversy about the role of insulin as a risk factor for cardiovascular disease $[16,17]$. Information about the association of insulin concentrations with CHD and other forms of atherosclerotic vascular disease in patients with Type II diabetes is limited and controversial [18-25]. Therefore, we investigated the predictive value of fasting plasma insulin and a cluster of cardiovascular risk factors associated with hyperinsulinaemia with respect to the risk of death from CHD in a large number of middleaged patients with Type II diabetes.

\section{Subjects and methods}

Baseline study. All diabetic patients in Finland who need antidiabetic drug therapy receive it free of charge according to the Sickness Insurance Act. The Social Insurance Institution maintains a central register of diabetic subjects receiving drug reimbursement. Based on this register, we identified all diabetic patients aged 45-64 years who were born and have been living in the Kuopio University Hospital district (East Finland) and in the Turku University Central Hospital district (West Finland). From this data source, the patient population enrolled in this study consisted of 510 diabetic subjects (253 men, 257 women) from East Finland (participation rate $83 \%)$ and 549 diabetic subjects (328 men, 221 women) from West Finland (participation rate $79 \%$ ) as has been described previously in detail [26]. Type I (insulin-dependent) diabetes was excluded in all insulin-treated patients with Type II diabetes by C-peptide measurements. All patients included in the final study population had plasma C-peptide concentration of at least $0.20 \mathrm{nmol} / 16 \mathrm{~min}$ after injection of $1 \mathrm{mg}$ of intravenous glucagon. A cut-off point of $0.20 \mathrm{nmol} / \mathrm{l}$ was chosen because postglucagon C-peptide concentrations below this limit have been shown to be associated with the occurrence of ketoacidosis in insulin-treated diabetic subjects [27]. None of the patients included in the study population and classified as having Type II diabetes according to the World Health Organization (WHO) criteria [28] had a history of ketoacidosis. Of the 510 patients with Type II diabetes from East Finland, 46 men and 38 women were treated with diet only, 183 men and 175 women with oral hypoglycaemic drugs, and 24 men and 44 women with insulin. Of 549 patients with Type II diabetes from West Finland, 46 men and 17 women were treated with diet only, 227 men and 177 women with oral hypoglycaemic drugs, and 55 men and 27 women with insulin.

Patients treated with insulin $(n=150)$ and those with missing plasma insulin data $(n=7)$ were excluded from statistical analyses. The final study population consisted of 228 men and 211 women from East Finland and 271 men and 192 women from West Finland. The age of diabetic men from East Finland was $56.8 \pm 0.3$ years and from West Finland $57.2 \pm 0.3$ years and the age of diabetic women from East Finland was $58.9 \pm 0.3$ and from West Finland $58.7 \pm 0.3$ years. The study programme for diabetic subjects which has been described previously in detail included one outpatient visit to the clinical research unit of the University of Kuopio or the rehabilitation research centre of the Social Insurance Institution in Turku [26]. The visit included an interview about the history of chest pain suggestive of $\mathrm{CHD}$, smoking, alcohol intake, physical activity and the use of drugs. All medical records of the subjects who reported that they had been admitted to the hospital because of chest pain were reviewed. Review of the medical records was done by M. Laakso in Kuopio and T. Rönnemaa in Turku after a careful standardisation of the methods and after training sessions among the reviewers. The WHO criteria for verified definite or possible myocardial infarction (MI) based on symptoms of chest pain, ECG changes, and enzyme determinations were used in the ascertainment of the diagnosis of previous MI [29].

Blood pressure was measured in the sitting position after a 5-min rest with a mercury sphygmomanometer and read to the nearest $2 \mathrm{mmHg}$. A subject was classified as having hypertension if he was receiving antihypertensive drugs or if his systolic blood pressure was at least 160 or diastolic blood pressure at least $95 \mathrm{mmHg}$.

Weight and height were measured in light clothing without shoes. Body mass index (BMI) was calculated by weight in $\mathrm{kg}$ divided by height in $\mathrm{m}$ squared. Triceps skin fold thickness, an indicator for central obesity, was measured on the dorsal aspect of the right arm at the middle point of the line from the acromion to the tip of the elbow with the Harpenden caliber (British Indicators, J. Bull, UK) with the subject standing and arms freely hanging down.

All laboratory specimens were drawn after a 12-h fast at 0800 hours. The analyses were carried out in duplicate. Plasma insulin concentration was determined by a commercial radioimmunoassay method (antisera M8170 and M8309, Novo, Copenhagen, Denmark). The day-to-day and intra-assay variations were $8.4 \%$ and $7.0 \%$, respectively. Fasting plasma glucose was determined by the glucose oxidase method (Boehringer, Mannheim, Germany). Glycated haemoglobin $\mathrm{A}_{1}$ was determined by affinity chromatography (Isolab, Akron, Ohio, USA). The plasma C-peptide response to glucagon was assessed according to the method of Faber and Binder [30]. Serum lipids and lipoproteins were determined from fresh serum samples drawn after a 12-h overnight fast. Serum total cholesterol and triglycerides were assayed by automated enzymatic methods (Boehringer, Germany). Serum HDL cholesterol was determined enzymatically after precipitation of low-density and very low-density lipoproteins with dextran sulphate$\mathrm{MgCl}_{2}$ [31]. Low density lipoprotein (LDL) cholesterol $(\mathrm{mmol} / \mathrm{l})$ was calculated using the Friedewald formula as follows: LDL cholesterol $=$ total cholesterol - HDL cholesterol $0.45 \mathrm{x}$ total triglycerides. Total urinary protein concentration was measured from the morning spot urine specimen with the Coomassie brilliant blue method (Bio-Rad Laboratories, Hercules, Calif., USA).

Follow-up study. All medical records of those subjects who died between baseline examination and December 31, 1989 were reviewed by S. Lehto. Copies of death certificates of those patients who had died were obtained from the files of the Central Statistical Office of Finland. To ensure that the data collection was complete, a computerised hospital discharge register was used to check hospital admissions of all participants of the baseline study. In the final classification of 
the causes of death hospital records and autopsy records were used, if available. The mortality data included in this article are mortality from CHD (International Classification of Diseases 9, Codes 410-414).

Statistical methods. Data analyses were carried out with the SPSSX and SPSS/PC + programs (SPSS Inc., Chicago, Ill., USA) The results for continuous variables are given as means \pm SEM and for categorial variables as percentages. The differences between the groups were assessed by the $\chi^{2}$ test, or Student's two tailed $t$ test for independent samples, when appropriate. Because insulin and triglyceride concentrations were not normally distributed, they were log transformed in all statistical analyses. Factor analysis was used to investigate relationships among several correlated variables by identifying presumed underlying "factors". Factor analysis is essentially a three-step process; firstly, extraction of the initial components using principal component analysis; secondly, rotation of the principal components resulting in elucidation of factors, and thirdly, interpretation of the factors $[32,33]$. Unstandardised variables, reflecting characteristics of the insulin resistance syndrome, included in the factor analysis were chosen a priori. Principal components were rotated using the ortogonal varimax method. Factor loadings greater than $0.40(p<0.05)$ were used to define a significant relationship. The final number of factors was limited to four. Univariate and multivariate Cox regression model [34] was used to investigate the association of cardiovascular risk variables or "factors" first determined by factor analysis with the incidence of death from CHD. Mantel-Haenszel's test for linear association was used to evaluate the association of the tertiles of plasma insulin with the risk of CHD mortality.

Approval of ethics committee. This study was approved by the ethics committees of the Kuopio University Central Hospital and the Turku University Central Hospital. All study subjects gave informed consent.

\section{Results}

During the 7-year follow-up (mean follow-up was 7.2 years in men and women) 142 men $(28.5 \%)$ and 96 women $(23.8 \%)$ with Type II diabetes died and 118 patients [81 men $(16.2 \%), 37$ women, $(9.2 \%)$ ] died of CHD. Mortality data of our study with respect to the East-West difference have been published previously [35].

Table 1 summarises baseline characteristics of patients with Type II diabetes in relation to CHD mortality. Data from East and West Finland were combined because no significant differences existed between these areas concerning cardiovascular risk factors with respect to death from CHD. Men who died of CHD were significantly older, had more often a history of a previous MI and had higher concentrations of total and LDL cholesterol and total triglycerides than men who survived. In addition, plasma glucose and insulin concentrations were higher and triceps skinfold thicker in male subjects who died of CHD during the follow-up than in those who survived. Women who died of CHD were older, had more often a history of a previous MI and had significantly higher fasting total triglyceride and glucose concentrations than women who survived.

Figure 1 shows CHD mortality of diabetic men, diabetic women and both sexes combined by tertiles of fasting plasma insulin. Coronary heart disease mortality increased with increasing plasma insulin concentrations, and the increase was statistically significant in men $(p=0.006)$ and in both sexes combined $(p=0.010)$ but not in women $(p=0.090)$. Adjustment was carried out with the Cox regression model for confounding variables to assess whether the predic-

Table 1. Levels of cardiovascular risk factors in relation to coronary heart disease (CHD) death during 7-year follow-up in patients with Type II diabetes

\begin{tabular}{|c|c|c|c|c|c|c|}
\hline \multirow[t]{2}{*}{ Variable } & \multicolumn{2}{|c|}{$\begin{array}{l}\text { Men } \\
\text { Death from CHD }\end{array}$} & \multirow[b]{2}{*}{$p$} & \multicolumn{2}{|c|}{$\begin{array}{l}\text { Women } \\
\text { Death from CHD }\end{array}$} & \multirow[b]{2}{*}{$p$} \\
\hline & $\begin{array}{l}\text { No } \\
(n=418)\end{array}$ & $\begin{array}{l}\text { Yes } \\
(n=81)\end{array}$ & & $\begin{array}{l}\text { No } \\
(n=366)\end{array}$ & $\begin{array}{l}\text { Yes } \\
(n=37)\end{array}$ & \\
\hline Age (years) & $57.1 \pm 0.2$ & $59.3 \pm 0.5$ & 0.001 & $58.8 \pm 0.2$ & $61.6 \pm 0.4$ & $<0.001$ \\
\hline Body mass index $\left(\mathrm{kg} / \mathrm{m}^{2}\right)$ & $28.4 \pm 0.2$ & $28.9 \pm 0.5$ & NS & $30.7 \pm 0.3$ & $31.2 \pm 0.9$ & NS \\
\hline Triceps skinfold (mm) & $12.9 \pm 0.3$ & $15.3 \pm 0.9$ & 0.004 & $25.5 \pm 0.4$ & $26.6 \pm 1.3$ & NS \\
\hline Previous MI (\%) & 15.8 & 43.2 & $<0.001$ & 7.9 & 18.9 & 0.025 \\
\hline Insulin $(\mathrm{pmol} / 1)$ & $124.5 \pm 4.3$ & $156.5 \pm 10.8$ & 0.003 & $138.5 \pm 4.5$ & $149.1 \pm 11.0$ & NS \\
\hline Total cholesterol (mmol/l) & $6.39 \pm 0.07$ & $6.98 \pm 0.16$ & 0.001 & $6.94 \pm 0.09$ & $7.30 \pm 0.30$ & NS \\
\hline LDL cholesterol $(\mathrm{mmol} / \mathrm{l})^{\mathrm{a}}$ & $4.25 \pm 0.05$ & $4.63 \pm 0.13$ & 0.020 & $4.58 \pm 0.66$ & $4.59 \pm 0.25$ & NS \\
\hline HDL cholesterol $(\mathrm{mmol} / \mathrm{l})$ & $1.15 \pm 0.02$ & $1.11 \pm 0.03$ & NS & $1.26 \pm 0.20$ & $1.15 \pm 0.06$ & NS \\
\hline Triglycerides $(\mathrm{mmol} / \mathrm{l})$ & $2.36 \pm 0.10$ & $3.00 \pm 0.22$ & 0.011 & $2.64 \pm 0.14$ & $3.82 \pm 0.65$ & 0.014 \\
\hline Plasma glucose $(\mathrm{mmol} / \mathrm{l})$ & $11.0 \pm 0.2$ & $12.2 \pm 0.4$ & 0.009 & $11.9 \pm 0.2$ & $13.5 \pm 0.6$ & 0.025 \\
\hline
\end{tabular}

Data are means \pm SEM or \%. MI indicates myocardial infarction (hospital verified and/or Q/QS change), LDL indicates

low-density lipoprotein, HDL indicates high-density lipoprotein. ${ }^{\text {a }}$ Calculated LDL cholesterol 

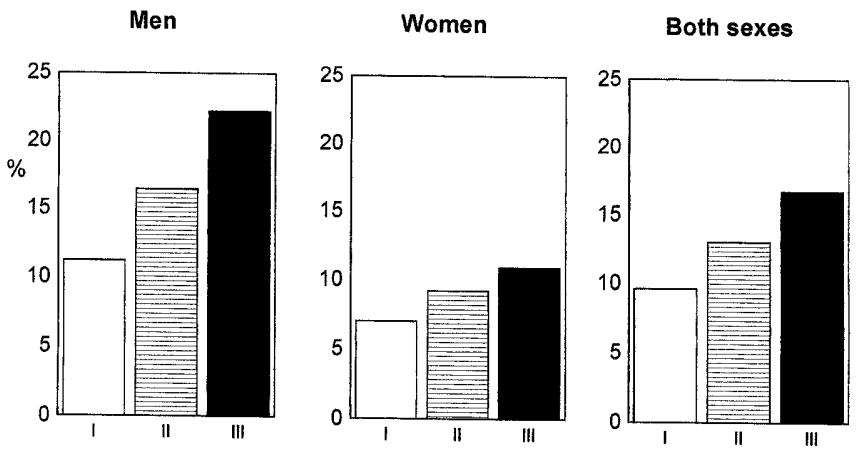

Fig. 1. The 7-year incidence (\%) of coronary heart disease mortality in patients with Type II diabetes according to the tertiles of plasma insulin. I, lowest; II middle; III, highest tertile (low $<86.8 \mathrm{pmol} / \mathrm{l}$; middle $86.8-140.8 \mathrm{pmol} / \mathrm{l}$; high $>140.8$ pmol/l). Men, $p=0.006$; women, $p=0.090$; both sexes, $p=0.010$

tive value of high fasting plasma insulin defined by cut-off point for the highest tertile ( $\geq 140.8 \mathrm{pmol} / \mathrm{l}$ ) was independent of factors known to have an impact on the risk of CHD (Table 2). Adjustment for age, sex and area of residence did not abolish the association of high plasma insulin with CHD. Similarly, further adjustment for general major CHD risk factors, serum cholesterol, smoking, and hypertension did not result in any significant decrease in the hazard ratio (HRs). Adjustment for serum triglycerides, serum HDL cholesterol and BMI, closely linked with hyperinsulinaemia and insulin resistance, however, resulted in a decrease in HRs below the level of conventional statistical significance (Table 2). The results were essentially similar when insulin was included into the model as a continuous variable.

The results of factor analysis (varimax-rotated factor matrix) are listed in Table 3. Firstly, the principal component analysis extracted four components all of which had eigenvalues greater than 1.0 and which were retained for rotation. Factor 1 was characterised by positive factor loadings for sex, BMI and triceps skinfold (central obesity). Factor 2 was characterised by high positive factor loadings for components of insulin resistance syndrome, for BMI, triglycerides and fasting insulin and a high negative loading for HDL cholesterol. Urinary protein, total cholesterol, triglycerides and glucose were loaded on Factor 3. When glucose was replaced by glycated haemoglobin $\mathrm{A}_{1}$ the results remained unchanged (data not shown). Factor 4 was characterised by positive loadings for age and hypertension and a negative loading for smoking. Factor analysis carried out separately for men and women gave essentially similar results (data not shown).

Table 4 shows area-adjusted HRs and their 95\% confidence intervals (CI) for different factors to predict CHD mortality in patients with Type II diabetes estimated by the Cox regression analysis. Factor 1 (obesity and sex factor) was inversely associated
Table 2. Adjusted hazard ratios and their $95 \%$ confidence intervals (CI) for hyperinsulinaemia (>140.8 pmol/1) to increase the risk for coronary heart disease mortality (118 of 902) during 7-year follow-up in patients with Type II diabetes estimated by Cox regression analysis

\begin{tabular}{|c|c|c|}
\hline \multirow[t]{2}{*}{ Adjustment for } & CHD mortality & \multirow[b]{2}{*}{$p$} \\
\hline & Hazard ratio $(95 \% \mathrm{CI})$ & \\
\hline Age, sex, area & $1.51(1.05,2.17)$ & 0.026 \\
\hline $\begin{array}{l}\text { Age, sex, area, total cholesterol, } \\
\text { smoking, hypertension }\end{array}$ & $1.49(1.02,2.17)$ & 0.034 \\
\hline $\begin{array}{l}\text { Age, sex, area, smoking, } \\
\text { hypertension, HDL cholesterol, } \\
\text { total triglycerides }\end{array}$ & $1.28(0.86,1.89)$ & 0.217 \\
\hline $\begin{array}{l}\text { Age, sex, area, total cholesterol, } \\
\text { smoking, hypertension, HDL } \\
\text { cholesterol, total triglycerides, } \\
\text { body mass index, duration of } \\
\text { diabetes and previous history } \\
\text { of MI }\end{array}$ & $1.23(0.81,1.87)$ & 0.221 \\
\hline
\end{tabular}

HDL indicates high-density lipoprotein, MI indicates myocardial infarction (hospital verified and/or Q/QS change)

Table 3. Factor analysis for cardiovascular risk factors (varimax-rotated factor matrix) in patients with Type II diabetes

\begin{tabular}{lcccc}
\hline Variable & Factor 1 & Factor 2 & Factor 3 & Factor 4 \\
\hline Age & -.066 & -.020 & .040 & .782 \\
Sex & .771 & -.255 & .163 & .231 \\
Smoking & -.202 & .131 & .003 & -.618 \\
Hypertension & .161 & .345 & .029 & .512 \\
BMI & .661 & .504 & -.098 & -.038 \\
Triceps skin-fold & .889 & .191 & .078 & .112 \\
Urinary protein & -.178 & .191 & .466 & .166 \\
Total cholesterol & .117 & .191 & .810 & -.036 \\
HDL-cholesterol & .168 & -.761 & -.139 & .058 \\
Total triglycerides & .108 & .544 & .692 & -.017 \\
Glucose & .086 & .036 & .586 & -.009 \\
Insulin & .341 & .706 & .001 & .063 \\
\hline
\end{tabular}

BMI indicates body mass index, HDL indicates high-density lipoprotein

with CHD mortality ( $p=0.043$ ) mainly due to lower mortality for diabetic women than for diabetic men. Factor 2, which was characterised by high loadings for the components of insulin resistance syndrome, was a strong predictor of CHD mortality $(p<0.001)$. Even if we added a previous history of MI into the model, Factor 2 still predicted death from CHD $(p=0.005)$. Similarly, Factor 3, characterised by generally known CHD risk factors (total cholesterol, triglycerides, glucose and urinary protein), was significantly associated with CHD mortality $(p<0.001)$. Factor 4, having positive loadings for age, and hypertension, and a negative loading for smoking was also significantly associated with CHD mortality $(p=0.007)$. 
Table 4. Area-adjusted hazard ratios (HR) and their $95 \%$ confidence intervals (CI) for different factors to predict coronary heart disease (CHD) mortality (118 of 902) in patients with Type II diabetes estimated by Cox regression analysis

\begin{tabular}{lllr}
\hline & \multicolumn{2}{l}{ CHD mortality } & \\
\cline { 2 - 3 } & HR & $(95 \% \mathrm{CI})$ & $p$ value \\
\hline Factor 1 & 0.82 & $(0.68,0.99)$ & 0.043 \\
Factor 2 & 1.43 & $(1.18,1.73)$ & $<0.001$ \\
Factor 3 & 1.28 & $(1.13,1.47)$ & $<0.001$ \\
Factor 4 & 1.29 & $(1.07,1.56)$ & 0.007 \\
\hline
\end{tabular}

\section{Discussion}

Our study shows that hyperinsulinaemia and cardiovascular risk factors clustering with hyperinsulinaemia (insulin resistance) are associated with death from CHD in patients with Type II diabetes. The predictive value of high fasting insulin with regard to death from CHD was independent of total cholesterol, smoking and hypertension, but not of risk factors clustering with hyperinsulinaemia because adjustment for the components of the insulin resistance syndrome (HDL cholesterol, triglycerides, obesity) abolished the significant association between hyperinsulinaemia and death from CHD (Table 2). By applying factor analysis and principal component analysis we could, however, show that "hyperinsulinaemia cluster" was predictive of death from CHD in patients with Type II diabetes (Table 4), and this association was statistically significant even after adjustment for a previous history of MI, a strong predictor of CHD mortality [4]. This is a novel finding and indicates for the first time that clustering of cardiovascular risk factors with hyperinsulinaemia is associated with an excess risk for death from CHD in patients with Type II diabetes.

The hypothesis that elevated concentrations of insulin might contribute to the risk of atherosclerosis was first presented in the $1960 \mathrm{~s}$. Two studies from England and Finland indicated that patients with MI had increased insulin concentrations after an oral glucose load [36, 37]. Since then, evidence from experimental, clinical and epidemiological studies has been published to support this hypothesis [14]. No consensus has, however, been reached on the notion that hyperinsulinaemia significantly contributes to the risk of CHD in the same way as do the classic risk factors, high cholesterol, hypertension and smoking $[13,16$, 17].

No studies are available in which insulin resistance had been measured and associated with the risk of future CHD events. All epidemiological evidence from prospective population based studies is based on the association of hyperinsulinaemia and CHD. Although fasting and insulin concentrations after a glucose load correlate quite well with insulin sensitivity evaluated by the euglycaemic clamp technique, this correlation is at most from 0.60 to 0.70 [38]. Therefore, it is not clear how closely the findings from the prospective studies based on insulin determinations can be used as an argument for or against the hypothesis that insulin resistance is a determinant of CHD. In patients with Type II diabetes insulin concentrations are even more difficult to interpret than in non-diabetic subjects. Type II diabetes is characterised not only by insulin resistance but also by insulin deficiency and therefore, the correlation of insulin concentrations with insulin resistance is much lower than in normoglycaemic subjects [38]. Therefore, a positive relation of high insulin concentrations with CHD in patients with Type II diabetes rather underestimates than overestimates the true association between these variables.

In non-diabetic subjects several prospective epidemiological studies have shown that hyperinsulinaemia predicts the risk of CHD [13]. Our 3.5 year follow-up study of elderly non-diabetic subjects showed that hyperinsulinaemia predicts death from CHD in multivariate analyses [odds ratio 2.57 (1.07-6.18, $p=0.035)$ ] after adjustment of conventional cardiovascular risk factors [39] By applying factor analysis we recently showed, based on a 7-year follow-up of the same study cohort, that clustering of cardiovascular risk factors with hyperinsulinaemia predicted CHD events among men [40]. It was convincingly shown [41] that high fasting specific insulin was a strong independent predictor of ischaemic heart disease in non-diabetic subjects aged 45 to 76 years without CHD at baseline. Moreover, the most recent one, the 22-year follow-up of Helsinki Policeman Study, showed that hyperinsulinaemia was a strong independent risk factor for CHD and its predictive power was of the same magnitude as that for cholesterol, although attenuating with lengthening follow-up time [15].

Information on the association of hyperinsulinaemia with the risk of CHD and other forms of atherosclerotic vascular disease in patients with Type II diabetes is still limited and controversial. Some cross-sectional studies have shown that Type II diabetes patients with atherosclerotic vascular disease have higher concentrations of fasting plasma insulin or C-peptide or higher postglucose plasma insulin levels than those without atherosclerotic vascular disease [18-21]. In a 5-year follow-up study of patients with newly diagnosed Type II diabetes high fasting insulin was found to be associated with the incidence of new ischaemic ECG abnormalities [19]. The Paris Prospective Study showed that during an 11-year followup high fasting plasma insulin predicted the risk of death from CHD in both Type II diabetic and non-diabetic subjects [22] but no adjustment was made for other risk factors. In a 6-year follow-up of the Diabetes Intervention Study high fasting insulin was associated with the development of MI independently of 
other risk factors in patients with Type II diabetes [23]. In the UK Prospective Diabetes Study fasting insulin assessed by tertiles was positively correlated with the risk of MI but this correlation became non-significant after adjustment for other risk factors [12]. In contrast to these observations, in a 10-year follow-up of the "borderline" diabetic group of the Bedford Study a low 2-h post-glucose plasma insulin was associated with an increased risk of CHD events [24].

The central role of insulin resistance/hyperinsulinaemia and insulin deficiency in the pathogenesis of Type II diabetes is widely accepted [42]. Furthermore, cross-sectional studies have indicated that in patients with Type II diabetes high insulin concentrations cluster with lipid and lipoprotein abnormalities similarly as in subjects with normoglycaemia [43-47]. Association of hyperinsulinaemia/insulin resistance with central obesity $[48,49]$ and arterial stiffness [50] is well documented in patients with Type II diabetes but the association with hypertension is controversial [51, 52]. Previous studies on non-diabetic subjects have indicated that a clustering of cardiovascular risk factors typical of insulin resistance syndrome can be shown by factor analysis [41, 53-54]. In another population study [54] three distinct factors were found. By applying factor analysis we could also find the clustering of disorders which characterise the insulin resistance syndrome (Table 3 ). Factor 2 could be called a hyperinsulinaemia factor because it was characterised by positive loadings for fasting plasma insulin, BMI, hypertension, total triglycerides, and a negative loading for HDL cholesterol. This "hyperinsulinemia cluster" predicted significantly death from CHD.

Our results have several implications. Firstly, our study shows that not only in non-diabetic subjects but also in patients with Type II diabetes factor analysis is able to extract a factor having high loadings for insulin and other components of the insulin resistance syndrome. Secondly, our study shows that conventional statistical methods which are based on the independence of different variables to predict an endpoint underestimate the role of hyperinsulinaemia to predict CHD. Thirdly, our study adds to the evidence that "hyperinsulinaemia cluster" can enhance the risk of cardiovascular disease in patients with Type II diabetes. This result has often been implicated but not proven previously.

Our study has limitations. Our insulin assay available since the beginning of 1980 s measures not only specific insulin but also proinsulin and des 31.32 proinsulin. The latter comprise about $10 \%$ of insulinlike molecules in non-diabetic subjects. Patients with Type II diabetes have a disproportionate increase of proinsulin concentrations [55-57]. Therefore, we cannot completely exclude the possibility that high concentrations of proinsulin could contribute to the risk of CHD in patients with Type II diabetes. It is, how- ever, unlikely that proinsulin or split products of insulin could have confounded the association between hyperinsulinaemia and CHD because the relation between specific and total immunoreactive insulin and other metabolic risk factors is similar in non-diabetic subjects [58] and in patients with Type II diabetes [59]. Cardiovascular risk factor levels might also have been influenced by the diagnosis of CHD before the baseline study particularly among patients who during the follow-up died of CHD. For example, smoking was somewhat less frequent among female diabetic patients who died of CHD than among female diabetic patients who did not die of CHD and therefore factor analysis on the relation between smoking, age and hypertension might be biased (Table 3). Furthermore, factor loadings for age and smoking were variable between different factors and it was difficult to draw any definite conclusions from factor analysis on the association of age and smoking in this patient population. Life-style modifications are, however, likely to weaken, not to strenghten, the association of cardiovascular risk factors (including hyperinsulinaemia) with CHD mortality.

In conclusion, our results support the notion that cardiovascular risk factors clustering with hyperinsulinaemia increase the risk of coronary heart disease in patients with Type II diabetes. Weight loss obtained by diet or exercise or both leading to the normalisation of hyperinsulinaemia should be benefical in the prevention and treatment of coronary heart disease events in patients with Type II diabetes.

\section{References}

1. Laakso M, Lehto S (1997) Epidemiology of macrovascular disease in diabetes. Diabetes Rev 5: 294-315

2. Kannel WB, McGee DL (1979) Diabetes and cardiovascular disease. The Framingham study. JAMA 241: 2035-2038

3. Stamler J, Vaccaro O, Neaton J, Wentworth D, for the Multiple Risk Factor Intervention Trial Research Group (1993) Diabetes, other risk factors, and 12-yr cardiovascular mortality for men screened in the Multiple Risk Factor Intervention Trial. Diabetes Care 16: 434-444

4. Haffner SM, Lehto S, Rönnemaa T, Pyörälä K, Laakso M (1998) Mortality from coronary heart disease in subjects with type 2 diabetes and in non-diabetic subjects with and without prior myocardial infarction. N Engl J Med 399: 229-234

5. Laakso M, Lehto S, Penttilä I, Pyörälä K (1993) Lipids and lipoproteins predicting coronary heart disease mortality and morbidity in patients with non-insulin-dependent diabetes. Circulation 88: 1421-1430

6. Goldberg RB (1981) Lipid disorders in diabetes. Diabetes Care 4: 561-572

7. Howard BV, Savage BJ, Bennion LJ, Bennett PH (1978) Lipoprotein composition in diabetes mellitus. Atherosclerosis 30: $153-162$

8. Laakso M, Barrett-Connor E (1989) Asymptomatic hyperglycaemia is associated with lipid and lipoprotein changes favouring atherosclerosis. Arteriosclerosis 9: 665-672 
9. Laakso M, Voutilainen E, Sarlund H, Aro A, Pyörälä K, Penttilä I (1985) Serum lipids and lipoproteins in middleaged non-insulin-dependent diabetics. Atherosclerosis 56: 271-281

10. Kuusisto J, Mykkänen L, Pyörälä K, Laakso M (1994) NIDDM and its metabolic control predict coronary heart disease in elderly subjects. Diabetes 43: 960-967

11. Lehto S, Rönnemaa T, Haffner SM, Pyörälä K, Kallio V (1997) Dyslipidemia and hyperglycemia predict coronary heart disease events in middle-aged patients with NIDDM. Diabetes 46: 1354-1359

12. Turner RC, Millns H, Neil HAW et al. (1998) Risk factors for coronary artery disease in non-insulin dependent diabetes mellitus: United Kingdom Prospective Diabetes Study (UKPDS:23). BMJ 316: 823-828

13. Ruige JB, Assenfelt WJJ, Dekker JM, Kostense PJ, Heine RJ, Bouter LM (1998) Insulin and risk of cardiovascular disease. A meta-analysis. Circulation 97: 996-1001

14. Laakso M (1996) Insulin resistance and coronary heart disease. Curr Opin Lipidol 7: 217-226

15. Pyörälä M, Miettinen H, Laakso M, Pyörälä K (1998) Hyperinsulinemia predicts coronary heart disease risk in healthy middle-aged men. The 22-year follow-up results of the Helsinki Policemen Study. Circulation 98: 398-404

16. Jarrett RJ (1994) Why is insulin not a risk factor for coronary heart disease? Diabetologia 37: 945-947

17. Wingard DL, Barrett-Connor EL, Ferrara A (1995) Is insulin really a heart disease risk factor? Diabetes Care 18: 1299-1304

18. Santen RJ, Willis PW, Fajans SS (1972) Atherosclerosis in diabetes mellitus. Correlation between serum lipid levels, adiposity and serum insulin level. Arch Intern Med 130: 833-843

19. Hillson RM, Hockaday TD, Mann JI, Newton DJ (1984) Hyperinsulinaemia is associated with development of electrocardiographic abnormalities in diabetics. Diabetes Res 1: 143-149

20. Standl E, Janka HU (1985) High serum insulin concentrations in relation to other cardiovascular risk factors in macrovascular disease of type 2 diabetes. Horm Metab Res 15 [Suppl]: S46-S51

21. Rönnemaa T, Laakso M, Pyöralä K, Kallio V, Puukka P (1991) High fasting plasma insulin is an indicator of coronary heart disease in non-insulin-dependent diabetic patients and nondiabetic subjects. Arterioscler Thromb 11: 80-90

22. Fontbonne A, Eschwege E (1987) Diabetes, hyperglycaemia, hyperinsulinaemia and atherosclerosis: epidemiological data. Diabetes Metab 13: 350-353

23. Hanefeld M, Schmechel H, Schwanebeck U, Lindner J, the DIS Group (1997) Predictors of coronary heart disease and death in NIDDM: The Diabetes Intervention Study experience. Diabetologia 40 [Suppl 2]S123-S124

24. Jarrett RJ, McCartney P, Keen H (1982) The Bedford Study: Ten year mortality rates in newly diagnosed diabetics, borderline diabetics and normoglycaemic controls and risk indices for coronary heart disease in borderline diabetics. Diabetologia 22: 79-84

25. Stout RW (1990) Insulin and atheroma: 20-year perspective. Diabetes Care 13: 631-654

26. Laakso M, Rönnemaa T, Pyörälä K, Kallio V, Puukka P, Penttilä I (1988) Atherosclerotic vascular disease and its risk factors in non-insulin-dependent diabetic and nondiabetic subjects in Finland. Diabetes Care 11: 449-463

27. Madsbad S, Alberti KG, Binder C et al. (1979) Role of residual insulin secretion in protecting against ketoacidosis in insulin-dependent diabetes. BMJ 2: 1257-1259
28. World Health Organization (1985) Diabetes mellitus. Report of WHO Study Group. WHO Technical Report Series No 727, World Health Organization, Geneva

29. World Health Organization (1983) Proposal for the Multinational Monitoring of Trends and Determinants in Cardiovascular Disease and Protocol (MONICA Project). World Health Organization, WHO/MNC/82.1 Rev. 1, Geneva

30. Faber OK, Binder C (1977) C-peptide response to glucagon: a test for the residual B-cell function in diabetes mellitus. Diabetes 26: 605-610

31. Kostner G (1976) Enzymatic determination of cholesterol in high density lipoprotein fractions prepared by polyanion precipitation. Clin Chem 22: 695-698

32. Kleinbaum DG, Kupper LL, Muller KE (1988) Applied Regression Analysis and Other Multivariable Methods. Kent Publishing, Boston

33. Stevens J (1986) Applied Multivariate Statistics for the Social Sciences. Lawrence Erlbaum Associates, Hillsdale, pp 337-350

34. Cox DR (1972) Regression models and life-tables. J R Stat Soc 34: 187-201

35. Laakso M, Rönnemaa T, Lehto S, Puukka P, Kallio V, Pyörälä K (1995) Does NIDDM increase the risk for coronary heart disease similarly in both low- and high-risk populations? Diabetologia 38: 487-493

36. Peters N, Hales CN (1965) Plasma insulin concentrations after myocardial infarction. Lancet i: 1144-1145

37. Nikkilä EA, Miettinen TA, Vesenne MR, Pelkonen R (1965) Plasma insulin in coronary heart disease: response to oral and intravenous glucose and tolbutamide. Lancet ii: $508-511$

38. Laakso M (1993) How good a marker is insulin level for insulin resistance? Am J Epidemiol 137: 959-965

39. Kuusisto J, Mykkänen L, Pyörälä K, Laakso M (1995) Hyperinsulinemic microalbuminuria. A new risk indicator for coronary heart disease. Circulation 91: 831-837

40. Lempiäinen P, Mykkänen L, Pyörälä K, Laakso M, Kuusisto J (1999) Insulin resistance syndrome predicts coronary heart disease events in elderly nondiabetic men. Circulation 100: 123-128

41. Despres JP, Lamarche B, Mauriege P et al. (1996) Hyperinsulinemia as an independent risk factor for ischemic heart disease. N Engl J Med 334: 952-957

42. DeFronzo RA, Bonadonna RC, Ferrannini E (1992) Pathogenesis of NIDDM. A balanced overview. Diabetes Care 15: 318-368

43. Orchard TJ, Becker DJ, Bates M, Kuller LH, Drash AL (1983) Plasma insulin and lipoprotein concentrations:an atherogenic association? Am J Epidemiol 118: 326-337

44. Laakso M, Pyörälä K, Voutilainen E, Marniemi J (1987) Plasma insulin and serum lipids and lipoproteins in middle-aged non-insulin-dependent diabetic and non-diabetic subjects. Am J Epidemiol 125: 611-621

45. Byrne CD, Wareham NJ, Day NE, McLeish R, Williams DRR, Hales CN (1995) Decreased non-esterified fatty acid suppression and features of the insulin resistance syndrome occur in a sub-group of individuals with normal glucose tolerance. Diabetologia 38: 1358-1366

46. Williams PT, Haskell WL, Vranizan KM, Krauss RM (1995) The associations of high-density lipoprotein subclasses with insulin and glucose levels, physical activity, resting heart rate, and regional adiposity in men with coronary artery disease: the Stanford Coronary Risk Intervention Project Baseline Survey. Metabolism 44: 106-114

47. Laakso M, Sarlund H, Mykkänen L (1990) Insulin resistance is associated with lipid and lipoprotein abnormalities 
in subjects with varying degrees of glucose tolerance. Arteriosclerosis 10: 223-231

48. Ferrannini E, Muscelli P, Stern MP, Haffner SM (1996) Differential impact of insulin and obesity on cardiovascular risk factors in non-diabetic subjects. Int J Obes 20: 7-14

49. Ludvik B, Nolan JJ, Baloga J, Sacks D, Olefsky J (1995) Effect of obesity on insulin resistance in normal subjects and patients with NIDDM. Diabetes 44: 1121-1125

50. Burchfiel CM, Curb JD, Sharp DS, Rodriques BL, Arakaki R, Chyo PH, Yano K (1995) Distribution and correlates of insulin in elderly men. The Honolulu Heart Program. Arterioscler Thromb Vasc Biol 15: 2213-2221

51. Ferrannini E, Buzzigoli G, Bonadonna R et al. (1987) Insulin resistance in essential hypertension. N Engl J Med 317: 350-357

53. Edwards KL, Austin MA, Newman B, Mayer E, Krauss R, Selby J (1994) Multivariate analysis of the insulin resistance syndrome in women. Arterioscler Thromb 14: 1940-1945

54. Meigs JB, D'Agostino RB, Wilson PW, Cupples LA, Nathan DM, Singer DE (1997) Risk variable clustering in the insulin resistance syndrome. The Framingham Offspring Study. Diabetes 46: 1594-1600
55. Ward WK, LaCava EC, Paquette TL, Beard JC, Wallum BJ, Porte D (1987) Disproportionate elevation of immunoreactive proinsulin in Type II (non-insulin-dependent) diabetes mellitus and in experimental insulin resistance. Diabetologia 30: 698-702

56. Saad MF, Kahn SE, Nelson RG et al. (1990) Disproportionately elevated proinsulin in Pima Indians with non-insulin dependent diabetes mellitus. J Clin Endocrinol Metab 70: $1247-1253$

57. Davis SN, Piatti PM, Monti L et al. (1993) Proinsulin and insulin concentrations following intravenous glucose challenge in normal, obese, and non-insulin-dependent diabetic subjects. Metabolism 42: 30-35

58. Haffner SM, Mykkänen L, Valdez RA, Stern MP (1990) Evaluation of two insulin assays in insulin resistance syndrome (Syndrome X). Arterioscler Thromb 14: 1430-1437

59. Nagi DK, Hendra TJ, Ryle AJ et al. (1990) The relationships of concentration of insulin, intact proinsulin and 32-33 split proinsulin with cardiovascular risk factors in Type II (non-insulin-dependent) diabetic subjects. Diabetologia 33: 532-537 